\title{
A Literatura Comparada e a ilusão do multiculturalismo
}

\author{
DOROTHYFIGUEIRA
}

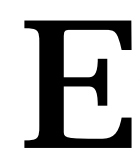

M 2000, a Associação Internacional de Literatura Comparada (ICLA) convocou sua assembléia trienal em Pretória, na África do Sul. O tema do congresso era "Os Caminhos do Multiculturalismo". Já mesmo em sua fa se de organização, eu estava desconfiada desse tópico. Nas instituições acadêmicas dos Estados U nidos, o termo "multiculturalismo" é suspeito; contudo, como qualquer número de outros "ismos", ele significa coisas diferentes para pessoas diferentes. Eu sentia que, para a ICLA, tanto melhor que ela estruturasse seu congresso em torno de um tema que, embora desacreditado nos círculos acadê micos nos Estados Unidos, pudesse evocar conotações positivas em outros luga res. As tendências americanas, pelo menos, não iam dominar essa conferência. Nos Estados U nidos, o "multiculturalismo" se tornou uma palava pretensamente técnica para os administradores da universidade. Ela está repleta de conotações politicamente vantajosas para as estruturas burocráticas que cortejam uma ima gem de diversidade. Eu estava curiosa do que essa palavra significava em outros contextos acadêmicos. No congresso da ICLA, aprendi que, embora não fosse um termo que senvisse de alvo para a zombaria, o sentido do multiculturalismo era igualmente vago em outros ambientes, não sugerindo geralmente mais do que diversidade.

Minha hostilidade com respeito ao multiculturalismo deriva de sua institucionalização nos Estados U nidos. As universidades aqui descobriram recentemente o valor de ensinar algo construído como "multiculturalismo". A virtude inerente do multiculturalismo repousa em seu apelo à novidade e à relevância. O multiculturalismo, do modo como é praticado nas instituições de ensino superior, também alimenta a necessidade intelectual de engajamento e a pretensão de que a crítica acadêmica pode funcionar como um ato político. A cultura ativista, parece, pode ser substituída pela cultura textual; no entanto, a quimera do multiculturalismo institucionalizado representa uma ameaça significativa à disciplina de Literatura Comparada e ao ensino da literatura mundial. Ela assumiu o controle das atividades de análise comparatista entre culturas e literaturas e alcançou essa importância em áreas que se apropriam do papel tradicional da Literatura Comparada. Além do cinismo declarado que por vezes enforma as iniciativas priorizadas - fundamentadas que estão no consumismo mercadológico que acabou definindo a academia - está o próprio fato de que esses locais que atualmente praticam o multiculturalismo, os departamentos de língua nacional e 
os institutos de humanidades, são com freqüência impróprios para a tarefa que assumiram. No caso dos departamentos de língua nacional, faltallhes alcance de visão para enxergar além de sua acalentada insularidade. Por necessidade de sobrevivência, é necessário competir pela posição cobiçada na condição de portavozes do campusem favor da teoria e da diversidade. Já que os departamentos de literatura nacional não são conhecidos por sua heterogeneidade, eles acham difícil corresponder a mandatos institucionais por diversidade. Eles podem compensar, contudo, colocando em seu currículo cursos que tratam das teorias da subalternidade e da Alteridade. Quando as tendências teóricas em voga coincidem com a língua da competência do departamento de literatura nacional, a unidade se beneficia com a capacidade de ler a teoria relevante no original, idealmente, com uma compreensão do contexto cultural e intelectual em que a crítica veio à luz; todavia, essa situação feliz raramente se dá. Os institutos de humanidades, centros ou programas se saem melhor. Eles podem funcionar facilmente como conglomerados transculturais (e uso o termo intencionalmente para ressaltar o aspecto de marketing dessas iniciativas).

O marketing nesse sentido é duplo. Primeiro, há marketing para os adminis tradores e reitores da universidade e através deles, que endossam a idéia da iniciativa multicultural como a abordagem maisavançada e "lógica” do Terceiro Mundo e o miasma das etnias em competição. Ele responde às necessidades institucionais de recrutar e "reestruturar", com respostas objetivas, as novas responsabilidades socioeconômicas. Em segundo lugar, o contexto multicultural permite que de terminados acadêmicos apareçam como luminares no panteão teórico/ crítico: eles então se vendem como astros da teoria e a universidade, por sua vez, os vende para atrair estudantes e ganhar dinheiro.

Os departamentos de literatura nacional podem se concentrar na teoria, embora se batam para lidar com a diversidade. Os programas de humanidades tendem a ser faltos de conhecimento básico lingüístico e intelectual. Eles aplicam a teoria ao texto sem o cuidado necessário quanto à situação histórica nacional e ao contexto exegético. O mais importante, contudo, é que os programas de literatura nacional e os institutos de humanidades não estão equipados com a metodologia nem com a inclinação para levar a efeito o trabal ho de comparação. I sso não os impediu de usurpar o papel e a função da Literatura Comparada em muitos campi nação afora.

Em contraste com a Literatura Comparada, essas unidades que revoga ram seu papel tradicional lêem o mundo em tradução. No caso dos institutos de humanidades, o estudo da língua é de pouca significação. Nos departamentos de literatura nacional, a aplicação de alguma tendência teórica se torna a "língua" da comunicação. Como alguém cujo trabalho toca o campo dos estudos asiáticos, preocupo-me com o modo como o Terceiro Mundo se enquadra nessa visão de multiculturalismo. Na década passada, trabalhei em três departamentos de 
literatura comparada com programas de Ph.D., todos grandes instituições públicas, um no Oriente, um no Meio-Oeste e um no Sul. Nas páginas que se seguem, gostaria de examinar muito brevemente o modo como o teatro do multiculturalismo teve um impacto sobre o ensino da literatura mundial na disciplina de Literatura Comparada, nesses vários locais.

Dez anos atrás, num programa da Universidade do Estado de New York (SU NY), a Literatura Comparada se achava num terreno cediço, localizado num departamento que abrangia outras unidades pequenas tão lógicas quanto os Es tudos Clássicos e tão heteróclitas quanto Religião, Budismo Coreano e Estudos Talmúdicos. A preocupação que existia com os textos esboroou-se com o estabelecimento de um instituto de humanidades bem financiado, no qual o superhumanista era um estudioso de vídeos musicais. A textualidade, porém, nunca se perdeu de todo. Ela aparecia nas discussões de caráter canônico cujos referentes eram histórias em quadrinhos, comentários reimpressos de jazz e cartas ao editor de Penthouse. Considerando a redefinição que o pósestruturalismo fez da cultura como texto, os estudos culturais permitiram que os professores titulares de literatura ensinassem qualquer coisa que pudesse ser lida e a valorassem como uma parte legítima do cânone.

Entretanto, mesmo antes dessas iniciativas inovadoras, os textos ensinados e lidos eram geralmente aqueles evocados pela teoria. Logo percebi que os aca dêmicosque defendem a diferença no nível da abstração obliteram freqüentemente a diferença na prática, ou atribuem sentido aos autores e obras que preenchem mais completamente suas expectativas teóricas. Assim, tínhamos um departa mento onde os estudantes conheciam os textos que mais facilmente se prestavam à teoria que, por sua vez, esses estudantes (ou, de preferência, os professores deles) favoreciam. Os estudantes tinham pouco conhecimento abrangente dos cânones literários, quer orientais quer ocidentais; mas havia uma autêntica indús tria caseira de leituras derridianas de Mallarmé, Rilke e Lao Tsé.

Eu então me mudei para a U niversidade de Illinois a fim de assumir um cargo em um departamento que, quatro dias depois, foi reestruturado. Ali, a situação era um pouco mais complexa, no entanto não estranha a muitos departamentos de Literatura Comparada. Um imenso Departamento de Inglês, estreitamente ligado a uma administração integrada sobretudo por cientistas, resolveu que aquele departamento deveria ser o porta-voz da teoria e do multiculturalismo no campus Professores de destaque, que por acaso eram monoglotas, falavam publicamente em fóruns nacionais do dinheiro dos contribuintes de Illinois sendo usado para financiar "estrangeiros demais". H ouve uma votação para dispersar a Literatura Comparada. Por um período de quatro anos, a administração vacilou. Devido ao fato de a Literatura Comparada ser, na época, considerada um departamento de "perfumaria", houve conversa sobre incorporála a um departamento mais amplo. Mas ninguém nos aceitaria, porque se acreditava esti- 
véssemos totalmente envolvidos com textos e estética. A Literatura Comparada continua a existir em Illinois como uma unidade independente, com apenas duas de suas faculdades com titulares permanentes [core faculty] subsistindo. Está em vias de ressuscitar com novas linhas, cujo compromisso é partilhado com outros departamentos. U m instituto de humanidades também foi formado para lidar com a teoria da tradução e a safra seguinte de "ismos". A ironia é que Illinois havia instalado um Departamento de Literatura Comparada que era transcultural e interdisciplinar. Seu compromisso com a comparação, a exegese e a competência lingüística fomentou o multiculturalismo em grau muito maior do que qualquer mandato institucional em que a diversidade é codificada em novas estruturas, mas no qual a análise comparativa talvez não seja mais a prioridade fundamental.

Atualmente, trabalho na Universidade da Geórgia, cujo departamento de Literatura Comparada tem 15 subdivisões e um currículo que, além de dar os cursos regulares de Literatura Comparada e Teoria, dá cursos de língua e litera tura chinesas, japonesas, coreanas, zulu, ioruba, suaili e hindi. Na verdade, esse departamento da Georgia tem potencial para lidar com o globo de maneira mais responsável do que a maioria dos Departamentos de Literatura Comparada; entretanto, deu-se uma situação curiosa que tornou esse departamento e o ensino da literatura mundial inúteis à população de graduandos.

$\mathrm{Na}$ Geórgia, temos o que um colega meu chamou de encontro de dois incomensuráveis. Havia um mandato universitário exigindo cursos de diversidade cultural. Esse mandato poderia ser interpretado em um sentido estrito (diversidade doméstica, norte-americana) ou em um sentido amplo (i. e., globalismo). No nível da universidade, os que queriam o foco estrito perderam esse debate. No nível da faculdade, contudo, a diversidade cultural foi entendida como multiculturalismo e este foi definido de maneira provinciana como doméstico. $\mathrm{O}$ nível da discussão não foi particularmente sofisticado. Os que privilegiavam um foco internacional foram acusados de estar defendendo uma posição de motivação racial. Considerando a história da Geórgia, essa retórica foi determinante. Os efeitos práticos no nível da faculdade foram os seguintes: $50 \%$ ou mais de leituras em todos os cursos de Literatura Comparada devem lidar com literatura nãoinglesa e não-americana (para distingui-las do Departamento de Inglês). A fim de preencher as exigências multiculturais, a maior parte do material do curso deve ser literatura étnica americana. Enquanto qualquer quantidade de cursos de literatura inglesa pode preencher as exigências dos programas de graduação em estudos multiculturais, os cursos de literatura mundial, por definição, não podem fazer isso. Como ocorre em muitos departamentos, nossos cursos de litera tura mundial fornecem apoio docente para os professores assistentes e os pós graduandos. Quando eles estão vazios, perdemos nossa raison d'être. Na condição de diretora, devo escrever aos pais da Geórgia assegurando que os filhos 
deles têm menos chances de se tornar neonazistas se lerem Wole Soyinka em vez de Alice Walker? O que começou como uma tentativa de combater a existência e/ ou percepção do racismo endêmico resultou em definir o globalismo no foco estreito da experiência étnica americana. A motivação era provavelmente sincera. Em sua institucionalização, tornou-se tendente à exclusão. A Geórgia fornece um excelente estudo de caso para a maneira pela qual palavras tais como multiculturalismo e globalismo assumem uma vida própria no ambiente universitário.

Permitam-me tentar tirar algumas conclusões significativas concernentes ao ensino da literatura mundial, a partir de minhas experiências nesses departa mentos de Literatura Comparada demograficamente representativos. Na última década, houve certa tendência a transformar todos os objetos culturais, quer superiores quer inferiores, em cultura popular. Para dar a esse fenômeno uma formulação mais estética: o kitsch triunfou. Ou, para formular a questão em termos teóricos: houve uma mudança de paradigma do textual para o cultural. Essa mudança foi facilitada pela suposição teórica de que tudo na verdade é um texto, especialmente todas as formas de atividade cultural, até mesmo formas escapistas de diversão. A radicalização da teoria teve também um impacto significativo sobre essa mudança de paradigma: poder-se-ia rejeitar a literatura como uma forma antiquada de capital cultural pertencente à burguesia; no entanto, a rejeição da literatura em favor dos estudos culturais tinha que ver menos com instalar um formato mais imediato e não tão conservador, e mais com uma necessidade ideológica de procurar a autovalidação através da identificação com as vítimas da repressão em termos globais. A necessidade humana de "exotizar" (ou estetizar) a experiência individual pode ser pungente, exceto quando se torna uma profissão.

De que forma o Terceiro Mundo se configura nesse esquema? Em muitas universidades americanas, o Terceiro Mundo existe sob a rubrica das literaturas pós-coloniais e estas são tratadas sob o guarda-chuva do multiculturalismo; todavia, os estudos pós-coloniais e multiculturais têm pouco a ver, de fato, com a realidade do Terceiro Mundo. O envolvimento retórico apenas se mascara em projeto de mudança social. Os críticos despendem pouco tempo, ou nenhum, perto dos locais nativos que eles simulam analisar, e não raro estão privados dos instrumentos essenciais com que estudar esses locais. Privada da especificidade cultural, uma experiência colonial pode vir a se parecer com outra. Em um contexto multicultural, esses locais idealmente seriam indistinguíveis. A história pode, pois, ser dividida em segmentos controláveis e isolados, com base na experiência do colonialismo moderno, enquanto ao mesmo tempo se reprova o falso essencialismo. Essas representações fragmentárias e a-contextuais são aceitas com um profundo cinismo, considerando o Outro como objeto fossilizado de experimentação clínica. Elites do Terceiro Mundo, instruidas como ocidental istas' ocidentais, dominam o discurso; sua linguagem se apóia nas epi stemes ocidentais, 
e seu conhecimento da literatura nacional ou do contexto histórico é comumente o de um indivíduo que se exercitou em literatura inglesa e em teoria crítica do século XX. O que passa por um cânone se concentra quase exclusivamente em textos ingleses, como se estes fossem verdadeiramente representativos da situa ção pós-colonial, ignorando (pace o Mahesweta Devi de Spivak) os textos verná culos que possam não lidar com o colonialismo. Isso levou a uma forma um tanto desacreditada de erudição e formação de cânone. I magine o leitor como se torna ridículo quando a literatura mundial, empacotada dessa forma, veio para satisfazer um mandato da universidade em prol da diversidade.

O Terceiro Mundo é, dessa forma, posto entre parênteses antes que a discussão comece $O$ interesse fundamental do crítico está em estruturar o Terceiro M undo tematicamente para um ambiente que consuma essas estruturas. U ma vez mais, temos o encontro dos incomensuráveis - uma necessidade profundamente enraizada na experiência do engajamento político dos anos 60 satisfazendo uma demanda dos anos 90: ser o "sabe-tudo" da mídia, empacotar e negociar o capital intelectual. Não deixa de ser irônico o modo como essas duas estruturas conceituais facilmente se combinaram. Se a crença na crítica como uma intervenção viável é uma relíquia arruinada dos anos 60, então todo o projeto crítico não funciona senão como uma investigação da impotência sócio-políticia. Onde está a potência? Ela reside no relacionamento do crítico com os colegas e na cunhagem e uso do jargão. A capacidade da manipulação da linguagem se torna um exercício de pirotecnia acumulando as questões críticas em um jogo lingüístico rarefeito. A teoria, entendida como capital simbólico e combinada com a condição de porta-voz, torna-se ainda mais uma forma de poder profissional. A quimera do multiculturalismo pemitiu que o crítico parecesse importante num nível global. O mundo real e a variedade de suas literaturas estão eclipsados por essa forma mais ampla de projeto hegemônico profissional.

Embora o apelo de Goethe para a formação de uma Weltliteratur e para enriquecer a própria cultura por meio do conhecimento de outros modelos de expressão artística tenha caído em descrédito, não deveríamos esquecer que a disciplina de Literatura Comparada se formou a partir do desejo cosmopolita de acolher a diversidade. Nosso campo teve início buscando envolver o mundo conhecido, se bem com instrumentos bastante insuficientes. Com o correr do tempo, ele se tornou institucionalmente muito menos global em sua perspectiva; todavia, mesmo em seus momentos mais eurocêntricos e isolacionistas, ele é preferível ao profundo cinismo do multiculturalismo tal como este é encarado nas universidades americanas de hoje. $O$ ensino da literatura mundial, empacotado na forma de multiculturalismo, tornou-se um joguete nas mãos de um grupo de professores e administradores universitários cínicos, que procuram legitimar um comprometimento político que nunca lograram inteiramente em tempos mais propícios. 
Contrariamente ao que possam sugerir as aulas de Literatura Mundial, as iniciativas multiculturais e as teorias da alteridade, o Terceiro M undo desafia o empacotamento. Continua a ser o tumulto de incomensurabilidades não passível de assimilação que encontramos nas consultorias de alta tecnologia e nos empórios de temperos da Buford H ighway, em Atlanta, e do Northern Boulevard, em Queens. Esse choque da inovação tecnológica com a real idade prosaica gera um caos que não pode ser homogeneizado nem encoberto pelo verniz teórico. Enquanto nós, estudiosos, não compreendermos que não deveríamos fazer o pape de "vítimas por procuração" (para citar o crítico Deepika Bahri), ou exóticos fin de siècle; enquanto não compreendermos que o Outro não pode ser consumido a baixo preço, nada teremos a oferecer a nossos alunos. I nevitavelmente, as verdades do momento nos estudos multiculturais serão desacreditadas e os jovens estudiosos, procurando novos "ismos", darão o passo para preencher o vazio. 0 que me inquieta é que essa nova disputa por relevância é, talvez, o único ponto essencial no jogo.

D orothy Figueira é professora-titular de Literatura Comparada da University of Georgia, EstadosU nidos.

Tradução deAlípio Correia deFranca Neto. O original em inglês-C omparative Literature and theilusi on of multiculturalism - encontra-seà disposição do leitor no IEA-USP para eventual consulta.

Texto originalmente publicado em Literary R esearch/R echerce Littéraire, v. 17, n. 34, AILC, The U niversity of Werstern, Ontario, Canadá. 